\title{
Can carbon dioxide laser substitute moxibustion?
}

\author{
Insoo Jang • Jongbae Park
}

Published online: 4 July 2008

(C) Springer-Verlag London Limited 2008

\section{Dear Editors}

We read with interest an article by Shen et al. reporting that combined $10.6 \mu \mathrm{m}$ carbon dioxide $\left(\mathrm{CO}_{2}\right)$ laser and $650 \mathrm{~nm}$ indium-gallium-aluminum-phosphide (InGaAlP) laser irradiation on patients with knee osteoarthritis is beneficial [1]. For a constructive debate in the academic arena, we would like to share our comments as follows: (1) The substitution of moxibustion by $\mathrm{CO}_{2}$ laser, as implied by the authors in 'laser moxa', is inappropriate, because of substantially different penetration depths and the patterns of heat transfer; (2) the claim of successful allocation concealment casts doubt, due to the significantly high dropout rate in the placebo control group.

Approximately $99 \%$ of the thermal energy of $\mathrm{CO}_{2}$ laser is absorbed less than $0.2 \mathrm{~mm}$ from the skin surface, no matter how intense it is [2]. The epidermis is usually less than $0.15 \mathrm{~mm}$ thick, and the dermis is $1-3 \mathrm{~mm}$ [3]; therefore $\mathrm{CO}_{2}$ laser cannot reach the deeper parts of the dermis. The term moxibustion covers a broad range of thermo-stimulation, from direct to indirect methods, using a moxa stick. Different methods create different patterns of heat transfer, i.e., conduction, infrared irradiation, and

This reply refers to the letter to the editor at http://dx.doi.org/10.1007/ s10103-007-0536-9.

I. Jang $\cdot$ J. Park $(\bowtie)$

Department of Physical Medicine and Rehabilitation,

School of Medicine, University of North Carolina,

Chapel Hill, Campus Box 7200, Room 1203, UNC Hospitals,

Chapel Hill, NC 27599-7200, USA

e-mail: jongbae_park@med.unc.edu

\section{Jang}

College of Korean Medicine, Woosuk University,

Woosuk University Hospital,

Junghwasan-dong, Jeonju,

Jeonbuk, South Korea convection. While the proportion of the patterns varies among diverse moxibustion, all moxibustion heat reaches the depth of subcutaneous tissues. This substantially differentiates $\mathrm{CO}_{2}$ laser from moxibustion [4].

A significantly higher drop-out rate in the control group [55\%, 95\% confidence interval $(\mathrm{CI}) 33 \%$ to $77 \%$ ] than in the experimental group $(10 \%, 95 \% \mathrm{CI} 0 \%$ to $23 \%)$ at 4 weeks indicates unblinding one way or another. Insignificant correct guessing between the two groups may mislead the status of blinding when this significantly different compliance and drop-out rate are not taken into consideration. Therefore, the success of blinding in the study is doubtful. It may be plausible that the participant in the control group noticed the lack of heat sensation that he or she might have anticipated, and hence became disappointed with the allocation, which resulted in the drop out.

In summary, we contend further discussion is necessary to approve the idea of substituting moxibustion with $\mathrm{CO}_{2}$ laser, and the interpretation of the findings reported in the study need cautious revisiting.

\section{References}

1. Shen X, Zhao L, Ding G, Tan M, Gao J, Wang L, Lao L (2008) Effect of combined laser acupuncture on knee osteoarthritis: a pilot study. Lasers Med Sci [Epub ahead of print]

2. Tunér J, Hode L (2002) Laser therapy: clinical practice and scientific background. Prima Books, Grängesberg, Sweden, pp 28 $33,92-7$

3. Sanders JE, Goldstein BS, Leotta DF, Richards KA (1999) Image processing techniques for quantitative analysis of skin structures. Comput Methods Programs Biomed 59:167-180. doi:10.1016/ S0169-2607(99)00003-6

4. Schieke SM, Schroeder P, Krutmann J (2003) Cutaneous effects of infrared radiation: from clinical observations to molecular response mechanisms. Photodermatol Photoimmunol Photomed 19:228-234. doi:10.1034/j.1600-0781.2003.00054.x 